DOSSIÊ TEMÁTICO: Vitalidade do sujeito e poder de formação: narrativas autobiográficas em diálogo

\title{
HISTÓRIAS DE VIDA E FORMAÇÃO DE CUIDADORAS DE IDOSOS
}

\author{
LIFE STORIES AND TRAINING OF CAREGIVERS OF THE ELDERLY
}

\section{HISTORIAS DE VIDA Y FORMACIÓN DE LOS CUIDADORES DE ANCIANOS}

\author{
Mónica Araújo \\ Universidade do Minho - Portugal \\ Teresa Sarmento \\ Universidade do Minho - Portugal
}

\begin{abstract}
Resumo: Este artigo tem como objetivo refletir sobre histórias de vida de cuidadoras ${ }^{1}$ de idosos, enquanto método de investigação em si mesmo e como modalidade (auto)formativa em contexto profissional. Num processo de construção de histórias de vida partilhamos do rememorar de pedaços de vida individuais, que se tornam formativamente significativos para narradores, bem como para o investigador que assim pode questionar modalidades novas de concretização epistemológica. $\mathrm{O}$ artigo baseia-se num processo investigativo com cuidadoras de pessoas da terceira idade. $\mathrm{O}$ escutar as suas vozes constitui, à partida, o reconhecimento pelo valor da sua vida, o que releva a pertinência política das histórias de vida no campo pessoal, bem como da investigação enquanto manifestação do entendimento de cada sujeito como participante no processo de construção de conhecimento social. A produção oral, realizada durante a entrevista dos atores sociais que se narram, permite uma entrega do sujeito à sua própria história, enaltecendo aquela que é a sua identidade e transmitindo-a, aos poucos, ao investigador. A vida individual é uma expressão criadora que, quando tornada conhecida aos ouvidos e análise do investigador, tende a criar interpretações polissémicas e questionamentos, potenciando novas possibilidades formativas e epistemológicas. Os resultados do estudo mostraram que as histórias de vida serviram três importantes dimensões: 1) a auto consciencialização e autoformação das participantes, 2) o nosso acesso, enquanto formadoras-investigadoras, ao conhecimento das mesmas e 3) o valor epistémico das histórias de vida no campo de conhecimento de profissionais do humano.
\end{abstract}

Palavras chave: Formação; Histórias de Vida; Cuidadoras de Idosos.

Abstract: This article aims to reflect on the life stories of elderly's caregivers ${ }^{2}$, as a method of investigation in itself and as a (self)training modality in a professional context. In a process of building life stories we share the memory of individual parts of life, which become formatively meaningful for narrators as well as for the researcher who can thus question new modalities of epistemological realization. The article is based on an investigative process with caregivers of elderly people. Listening to their voices constitutes, from the outset, the recognition of the value of their lives, which highlights the political relevance of life stories in the personal field, as well as of research, as a manifestation of

\footnotetext{
${ }^{1} \mathrm{O}$ uso do designativo feminino - Cuidadoras - justifica-se no facto de esta profissão ser exercida maioritariamente ou quase exclusivamente por mulheres.

${ }^{2}$ The use of the feminine designation - Caregivers - is justified in the fact that this profession is exercised mainly or almost exclusively by women.
} 
the understanding of each subject as a participant in the process of building social knowledge. The oral production, carried out during the interview of the social actors who are narrated, allows the subject to surrender his or her own story, exalting what is his or her identity and transmitting it, little by little, to the researcher. The life of each is a creative expression that, when made known to the ears and analysis of the researcher, tends to create controversial interpretations and questionings, enhancing new formative and epistemological possibilities. The life of each is a creater expression that, when made known to the ears and analysis of the researcher, tends to create controversial interpretations and questionings, enhancing new formative and epistemological possibilities. The results of the study showed that life stories served three important dimensions: 1) the self-awareness and (self-)trainig of the participants, 2) our access, as trainer-researchers, to their knowledge and 3) the epistemic value of life stories in the field of knowledge about professionals of human.

Keywords: Life Stories. Training. Elderly' Caregivers

Resumen: El presente artículo tiene por objeto reflexionar sobre las historias de vida de las cuidadoras ${ }^{3}$ de ancianos, como método de investigación en sí mismo y como modalidad (auto)formativa en un contexto profesional. En un proceso de construcción de historias de vida compartimos el recuerdo de trozos individuales de vida, que se vuelven formativamente significativos para los narradores así como para el investigador que puede así cuestionar nuevas modalidades de realización epistemológica. El artículo se basa en un proceso de investigación con cuidadores de personas mayores. Escuchar sus voces constituye, desde el principio, el reconocimiento del valor de su vida, lo que pone de relieve la relevancia política de las historias de vida en el ámbito personal, así como de la investigación, como manifestación de la comprensión de cada sujeto como participante en el proceso de construcción del conocimiento social. La producción oral, realizada durante la entrevista de los actores sociales que se narran, permite que el sujeto entregue su propia historia, alabando lo que es su identidad y transmitiéndolo gradualmente al investigador. La vida de cada uno es una expresión creativa que, cuando se da a conocer a los oídos y al análisis del investigador, tiende a crear interpretaciones y cuestionamientos controvertidos, potenciando nuevas posibilidades formativas y epistemológicas. Los resultados del estudio mostraron que las historias de vida servían para tres dimensiones importantes: 1) la autoconciencia y la (auto)formación de los participantes, 2) nuestro acceso, como formadores-investigadores, a su conocimiento y 3 ) el valor epistémico de las historias de vida en el campo del conocimiento de los profesionales humanos.

Palabras clave: Formacion. Historias de vida. Cuidadoras de ancianos

\section{INTRODUÇÃO}

As histórias de vida, enquanto metodologia de formação e de investigação, apresentam-se como uma modalidade que pode, efetivamente, ser um contributo maior para a prática da (auto)formação ou, como adverte Gaston Pineau (2006), de submissão; ou seja, acontecerá ou não autoformação dependendo de o sujeito realizar ou não uma reflexão sobre si próprio, retirando daí propósitos para o prosseguimento da sua forma de ser e de agir.

\footnotetext{
${ }^{3}$ El uso de la denominación femenina - Cuidadoras - se justifica en el hecho de que esta profesión es ejercida principalmente o casi exclusivamente por mujeres.
} 
As narrativas de si, sobre si - mormente, as histórias de vida - têm um poder de envolvimento contributivo sem igual, para o próprio e para o investigador, onde o sujeito que se narra, se conta e se exalta por meio das suas experiências de vida, viabilizando um trabalho de análise, interpretação e compreensão ao pesquisador, num entranhado processo em que a (auto)formação acontece e a produção de conhecimento ocorre.

Narrar a própria vida e aceitar tal como formação constitui um processo complexo, que exige a cada um contar-se, reviver os seus percursos, confrontar-se, expor-se, reavivar momentos, sentimentos, sensações e memórias nem sempre eufóricas. A memória é, aqui, uma capacidade insubstituível e funciona de forma seletiva. O sujeito olha para o seu passado como algo distante, com a certeza de que jamais poderá alterar algo que viveu ou (re)marcar a diferença, mas de que se pode apoderar para traçar trajetos novos. Enquanto seres humanos díspares, acreditamos que a diferença individual é o que nos destaca no meio da sociedade. As histórias de vida contam vidas. Acrescentam-nos. O nosso passado alimenta-nos e torna-nos seres capazes de agir e reagir dentro dos vários contextos que nos põem à prova diariamente, concedendo-nos estruturas idiossincráticas para vivermos. O ser humano é constituído de presente e de futuro, mas também muito do passado, assente em experiências que são alicerces para o ser e estar na profissão, sobretudo quando se labora no campo do humano como é o caso das cuidadoras de idosos.

Vivemos numa época em que a pandemia covid 19, provocada pelo vírus SARS2, se expande velozmente a nível mundial, dizimando sobretudo os idosos, em especial os que se encontram em lares residenciais; os que sobrevivem, encontram-se encerrados nessas residências, submetidos a medidas securitárias extremas, isolados socialmente e afastados físicamente, fechados, muitos deles, quarto a quarto, sem possibilidades de receberem visitas dos seus familiares. Neste contexto, realça-se o papel das suas cuidadoras, salientando-se, por um lado, a necessidade de se avançar rápida e profundamente na sua formação, e, por outro, salientando-se o seu enorme valor na garantia de transmissão de afetos e de segurança física e emocional aos que, por razões muito diversas, não podem passar a fase final das suas vidas no seio das suas famílias. Ser cuidador de idosos, como estes tempos tornam mais visível, exige, para além de competências técnicas, a expressão permanente da humanidade de cada um.

É, precisamente, a partir desta premissa que o nosso artigo singrará: o poder de envolvimento do sujeito baseado nas suas experiências de vida, consolidadas no momento da narração, em linguagem, em palavras, em diálogo, colocando-se em questionamento consigo próprio, em prol da autoformação, da autoconsciência e da autoemancipação para ser capaz de 
trabalhar com o Outro, num coletivo que não abafa mas inclui cada um dos atores sociais presentes no contexto profissional.

Com esse propósito damos voz a três mulheres diferentes, que conhecemos no decurso de um processo académico de formação pós-graduada ${ }^{4}$ com experiências e percursos distintos, com marcas de vida e objetivos dissemelhantes, que se cruzam num mesmo local para exercer a profissão de cuidadoras de idosos - uma profissão centrada no e para o Humano. O zelo e o cuidado pelo e com o Outro manifestam-se em todas as participantes como requisito naturalizado. Iniciamos a nossa pesquisa, com base nas seguintes questões: De tudo aquilo que as afasta enquanto seres humanos díspares, o que será que as aproxima como profissionais do mesmo ramo? Como se têm constituído como formativas as suas experiências de vida? A possibilidade de se narrarem é consciencializado pelas mesmas como autoformação?

A pesquisa permitiu-nos aceder, enquanto formadoras-investigadoras, ao conhecimento mais profundo das narradoras, compreendendo como se foi processando a consciencialização e autoformação das mesmas, confirmando assim a noção do valor epistémico das histórias de vida no campo de conhecimento de profissionais do humano.

\section{O humano na base da formação de cuidadoras de idosos}

Pensar em Cuidadoras de Idosos coloca-nos perante profissões sensíveis, no sentido em que pertencem ao grupo das Profissões do Humano e, portanto, em que a relação interpessoal é vital, exigindo um contacto próximo e assíduo, em que há uma grande possibilidade de se criarem conversas, trocas de experiências, afetos e amizades. Realmente, quanto a este aspeto e porque se presenciaram momentos assim durante o processo de investigação realizado em contexto real, consideramos que tal é vital para ambas as partes, até porque as pessoas de terceira idade, espontaneamente, requerem atenção redobrada, o que torna natural este tipo de afeições. Estas profissões levam à criação de uma relação baseada no toque e na confiança, o que transporta uma bagagem sentimental e emocional, em que o saber ser e o saber estar têm que caminhar ao lado do saber fazer.

O trabalho com a terceira idade, tal como as outras profissões, obriga o aperfeiçoamento do saber fazer por meio de práticas formativas, que intervêm como forma de

\footnotetext{
${ }^{4}$ Serviu de suporte a este artigo, um Relatório de Estágio redigido e orientado pelas autoras deste artigo. O trabalho em causa serviu fins investigativos e curriculares, sendo que pode ser acessado, na íntegra, no Repositorium da Universidade do Minho, disponível em: http://repositorium.sdum.uminho.pt/bitstream/1822/63738/1/M\%c3\%b3nica\%20Pires\%20Ara\%c3\%bajo.pdf
} 
dinâmica profissional, consolidação de conhecimentos, construção de novos e atingimento de objetivos de carreira. É importante esta construção de novas aprendizagens e, sobretudo, a abertura para tal, como forma dos sujeitos se livrarem de hábitos antigos e darem atenção àquilo que é mais criativo e melhor se adequa a cada realidade (JOSSO, 2010). Para além de ações formativas de cariz técnico que incentivem à melhoria da prática (saber fazer), são essenciais aprendizagens para incentivar o formando a gerir aquilo que lhe é interno e a aprender (ou exercitar) a prática da autorregulação. A formação técnica é muito importante, uma vez que os idosos requerem profissionais altamente capacitados para os apoiarem em termos físicos, anímicos e sociais; a par disso, urge incrementar ações que permitam aos sujeitos refletirem sobre si próprios, valorizando o seu caráter humano. A abordagem ao (auto)controlo por meio da inteligência emocional, a capacidade de gerir emoções perante a avaliação dos contextos, o reconhecimento dos próprios sentimentos e dos sentimentos dos outros, o evitar conflitos ou, ao invés, construir a empatia, são aspetos fulcrais quando se trata da formação do profissional do humano; ou seja, aspetos que contribuem para o desenvolvimento social do sujeito e para a sua aprendizagem de si e de relação com os outros.

A formação de cuidadoras de idosos ocupa, por isso, um lugar específico e desejável nos sujeitos, no desenvolvimento geral do indivíduo como forma de melhoria pessoal (para si próprio) e profissional (na ação que desenvolve com e para os outros), pelo que as experiências de vida, narradas e assim consciencializadas, se podem tornar recursos (auto)formativos fundamentais.

\section{A narrativa de si como prática (auto)formativa}

A prática da (auto)formação é um processo que se vai construindo à medida que as experiências de vida vão acontecendo, no entanto, nem todas as experiências são, à partida, formadoras para o sujeito. Josso (2010) revela-nos, neste sentido, que é crucial que se verifiquem três aspetos para que as experiências sejam formadoras para o sujeito e não meramente fortuitas; ou seja, para que se concretizem como formadoras as experiências têm de enriquecer o indivíduo, traduzindo-se por alguma mudança ou nova aquisição: o fator ter experiências - viver situações que não tenham sido provocadas pelo próprio; o fator fazer experiências - viver situações que tenham sido provocadas pelo próprio e, finalmente, pensar sobre as experiências - independentemente de quem as tenha proporcionado (JOSSO, 2010).

O interesse formativo baseado nas experiências pessoais é realçado sob dois pontos de vista. Em primeiro lugar, enquanto sustentáculo das histórias de vida, já que proporciona 
conhecimento para o narrador e para o investigador como sistema epistemológico de criação de conhecimento, onde o sujeito aprende de forma experiencial, "porque parte do princípio de que o sujeito toma consciência de si e de suas aprendizagens experienciais quando vive, simultaneamente, os papéis de ator e investigador da sua própria história" (JOSSO, 2010, p. 12). De seguida, do ponto de vista da valorização do capital intelectual e sensitivo, por exemplo, através de ações de formação que propiciem o desenvolvimento e potencial dos sujeitos, como forma de promover a valorização dos atores sociais, em busca da garantia da humanização dos serviços: enquanto estruturação de si mesmos e sobre o lugar que é ocupado na formação pelas experiências que permitem a construção e desconstrução de identidades e subjetividades.

Efetivamente, nos últimos anos tem-se assistido a uma enorme busca pela utilização da pesquisa autobiográfica e pelas histórias de vida, principalmente no campo da Educação, o que nos permite aceder a muitos dos atores sociais que desenvovem a sua vida e ação pessoal, de forma integrada, neste campo de atividade profissional.

Ao afirmarmos que a abordagem autobiográfica contribui para a formação do sujeito, convém que, acima de tudo, se explicite e reflita sobre os contornos que definem essa aceitabilidade e apropriação. Quando assistimos a uma narrativa autobiográfica, ouvimos um rememorar de factos individuais, a uma libertação do pensamento. Esta questão da rememoração é importante, porque enfatiza o uso da memória pelo sujeito. Desta memória mobilizamos os trajetos e experiências que produziram aprendizagem e, por isso, formadoras para o sujeito. Na relação entre sujeito, história de vida, contexto histórico e elaboração de sentimentos, acontece um processo de construção de conhecimento significativo. Assim sendo, podem surgir exatamente os mesmos sentimentos anteriormente ocasionados pelos contextos ou situações no indivíduo narrado, que ele lembra e não altera ou, por outro lado, podem surgir sentimentos diferentes, fruto do momento no qual se encontra e da visão que detém "hoje" face ao seu passado, das novas experiências vividas e as quais o (re)moldaram. Como referiram Ribeiro e Santos (2000, p. 49), o sujeito cria "um balanço de sua vida".

A produção oral, realizada durante a entrevista dos sujeitos que se narram, permite uma entrega do sujeito à sua própria história, enaltecendo aquela que é a sua identidade e transmitindo-a, aos poucos, ao investigador. O processo narrativo é intimamente acompanhado por um processo reflexivo. Paulo Freire (1970, p .45) afirma, a este respeito, que "o diálogo é este encontro dos homens, mediatizados pelo mundo, para pronunciá-lo, não se esgotando, portanto, na relação eu-tu."

A memória é, para além de um instrumento essencial e decisivo em todo este processo, um recurso "ditador", chamar-lhe-emos. A linguagem, enquanto instrumento indispensável 
neste processo, manifesta-se como ponte entre o pensamento do narrador e a escuta atenta do investigador. É a partir desta conversa que se gera informação e interação entre intervenientes, a chamada produção interaccionista (LECHNER, 2009). A memória é, assim, ditadora na medida em que seleciona o que deve ou não ser conhecido pelo Outro.

Os sujeitos narradores narram aquilo que é uma "ficção verdadeira do sujeito: ela é a história que o narrador, no momento em que a enuncia, tem por verdadeira, e ele se constrói como sujeito (individual e social) no ato de sua enunciação" (DELORY-MOMBERGER, 2006, p. 364). Ademais, há todo um trabalho ímpar e minucioso efetuado na fase de pós narração que o investigador atenta quando se debruça na análise da narrativa; a realidade dos estudos autobiográficos diz-nos que um dos fatores típicos da produção autobiográfica se baseia na não sequencialidade dos factos vividos pelo sujeito, ou seja, o sujeito recorre à memória sem grandes linhas de direção temporal, vai-se recordando aos poucos e entrelaçando estórias, independentemente do momento em que elas tenham ocorrido. Os espaços temporais cruzamse numa realidade proferida, mas não, necessariamente, numa "realidade", isto é, os relatos encontram-se na palavra, mas podem não ter ocorrido sequencialmente. Não existe, portanto, preocupação em narrar cronologicamente (PRADO \& SOLIGO, 2005).

Em relação a tal, Michael Pollak (1992) revela que

É como se, numa história de vida individual - mas isso acontece igualmente em memórias construídas coletivamente - houvesse elementos irredutíveis, em que o trabalho de solidificação da memória foi tão importante que impossibilitou a ocorrência de mudanças. (POLLAK, 1992, p. 201)

Há sempre uma relação entre memória individual e memória coletiva porque quando criamos memórias nossas, criámo-las com base nos grupos onde estamos inseridos, com origens, sentimentos, sensações variadas.

Ainda assim, cada sujeito tem a capacidade de atribuir a significação e ponto de vista face aos acontecimentos de forma individual. A valorização da individualidade eleva a capacidade do sujeito se (re)significar. Essa valorização é maior nos processos de subjetivação, os quais oferecem às autobiografias o poder de socialização.

A memória é, portanto, um espaço extremamente rico, que se vai multiplicando à medida que vamos criando lembranças. Neste sentido, chamar-lhe-íamos, também, um espaço hierarquizado, uma vez que se vai definindo conforme as nossas ações.

Se, por um lado, a memória pode ser voluntária, por outro lado, pode ser involuntária (SEIXAS, 2001). O primeiro tipo, diz a autora, com base em Bergson e Proust, ser aquele que "não atinge o pleno estatuto da memória, ela configura uma memória menor, essencial à vida, 
porém corriqueira e superficial" (SEIXAS, 2001, p. 45), assumindo-se como interna e indissociável do ser humano, equiparada a atos como "andar ou escrever" (ibidem). Frise-se, assim, que a relevância da memória voluntária para o momento narrativo, onde o sujeito se narra conforme as suas experiências de vida, permitindo-lhe apropriar-se dos seus pedaços de vida e transformando-os em formação. Ainda assim, é uma memória que, apesar de trabalhar com aquilo que diariamente "vê", não guarda essas imagens: é analisada como uma memória "enganadora" (SEIXAS, 2001, p. 46).

Muitas vezes, de forma involuntária, ocorrem memórias, as quais não mobilizamos intencionalmente mas que nos fazem momentos, situações que se tornam pertinentes no momento em que ocorrem, podendo até interferir com o rumo de muitas das nossas decisões. A memória é involuntária porque não é controlada, simplesmente irrompe, não acrescentando nem subtraindo nada ou sujeito (SEIXAS, 2001). Algo involuntário é algo que não é realizado por meio de ações ou dito por meio de palavras com intenção ou consciência de tal, portanto, durante uma autobiografia, aquilo que é transmitido de forma involuntária pode revelar aspetos importantes sem que, realmente, haja vontade do sujeito em divulgá-los.

A memória, no seu todo, vem contribuir para que, através do momento autobiográfico, possamos perceber e estruturar a personalidade do sujeito, por isso é crucial que não nos foquemos, somente, nos aspetos considerados positivos, mas também "nas hostilidades ocultas que fazem parte da história" (ANSART, 2001, p. 16).

$\mathrm{Na}$ verdade, perante as três histórias de vida de cuidadoras de idosos que suscitaram este artigo, há circunstâncias que nos levam a afirmar que o peso do que é negativo nas suas vidas se sobrepõe, de certa forma, aos aspetos positivos: o desemprego, o luto, as doenças, as perdas contínuas, as dificuldades financeiras ou a violência física e verbal, promoveram várias fases das três vidas contadas em contexto de investigação. Não nos é descabido afirmar que tais situações, muitas vezes combinadas e simultâneas, criaram efeitos drásticos nas personalidades destas cuidadoras, levando a ruturas não só externas mas internas também. Todas as participantes passaram por momentos de perdas, quer humanas quer materiais, que as obrigaram a lutar e a (re)encontrarem-se. Serão estas perdas um combustível às experiências formadoras? $\mathrm{Na}$ verdade, consideramos que há essa possibilidade, tendo em conta o material que se retirou das três análises. Aquilo que se perde, pode não constituir autoaprendizagem, mas promove a reflexão, podendo tornar-se conhecimento. Nos três casos, constatamos que a autoconsciência dos factos, a vontade, a capacidade e os contextos encontrados para se ampararem foram fatores essenciais à (trans)formação dos sujeitos. 
Ora, explicitemos este termo tão usado por Lechner (2009), quando se refere ao processo das histórias de vida como um todo. Na verdade, há aqui dois passos implícitos que precisamos ter em conta antes de assumirmos que a transformação, no geral, é o termo chave, o qual é enriquecido pelo termo formação e pelo prefixo trans, que, a nosso ver, adquirem posições importantes. O prefixo significa algo como através de, permitindo entender que, através do processo de formação, é criado um processo maior, o de mudanças profundas no sujeito, perante as aprendizagens ganhas por meio das experiências pessoais. $\mathrm{O}$ narrador, no instante em que se conta, atinge um momento de "transformação libertador" (LECHNER, 2009, p. 99), que muito coopera, assim, para a dimensão (trans)formadora do sujeito.

Ricoeur (1983) explicita que o ato narrativo opera segundo uma estrutura tripartida, sendo o primeiro campo a "experiência da mimese I" - aquilo que antecede a ação do sujeito; o campo da "composição narrativa em mimese II" - o tempo da ação e "mimese III" - quando se comunica e o motivo pelo qual se comunica a experiência a alguém.

Interessa-nos aqui realçar o terceiro campo, na medida em que a mimese III se manifesta como sendo a consolidação da narrativa, momento onde o narrador conta a sua história de vida a uma segunda pessoa, afirmando-se na sua própria história e procurando o seu sentido e significado. Este é um momento marcante, porque é através dele que o investigador acede ao cruzamento entre passado e presente do sujeito, constituindo-se então a identidade da narrativa. Há algo de extraordinário nesta fase que vai sendo revelado ao longo da narração: a identidade do sujeito (aquilo que o distingue), marcado pela sua abertura ao mundo (os grupos onde se insere, a sociedade que o acolhe e as experiências que tem). Além disso, neste terceiro campo, fala-se na relação instituída entre pesquisador e pesquisado ou, se quisermos e como melhor define o trabalho que foi realizado na base deste artigo, entre narrador e investigador. Durante a escuta atenta dos três relatos das histórias de vida, foi imprescindível o diálogo e o clima positivo de interação mantido com os sujeitos entrevistados, promotor de uma liberdade de expressão pessoal, de (trans)formação e de novas formas de (re)pensar o impacto da análise social nas vidas dos sujeitos.

As cuidadoras de idosos, aquando das entrevistas individuais ministradas para se conhecer as suas experiências de vida, expuseram momentos riquíssimos, involuntariamente manifestados diríamos, baseados nas formas como transmitiam essas experiências: as pausas nas narrativas, os questionamentos em voz alta, a forma como se narravam, a postura que mantinham ou as interjeições e risos foram contributos importantes para entendermos e deduzirmos aspetos das suas personalidades e, consequentemente, das suas histórias de vida. 


\section{As histórias de vida das três cuidadoras de idosos - memória e sua materialização}

As narrativas de si têm um poder enorme e constituem um desafio para o sujeito, onde este passa a expressar-se na primeira pessoa, a sua memória passa a ser um nicho rico de (auto)aprendizagem. A autobiografia é, por isso, um diálogo de singularização, dinâmica e emancipação que questiona, transforma e eleva o sujeito; quando partilhadas no âmbito de uma investigação, oferecem-se para a sua socialização e enriquecimento do conhecimento científico.

As narrativas individuais pertencentes às três cuidadoras de idosos são transformadas em vozes dissemelhantes, onde as suas experiências são passadas para a linguagem, em prol da (re)leitura das suas vidas. Este processo de recolha de histórias de vida é, ao mesmo tempo, um processo simples e complexo: simples no sentido de conhecimento das suas próprias vidas ninguém conhece melhor as suas experiências de vida do que os próprios sujeitos; e complexo no sentido da exposição: a abertura para tal não é sempre entendida nem acatada de bom grado.

Em contexto de investigação real propôs-se a três cuidadoras, Ana, Fernanda e Edna, que se narrassem as suas histórias de vida, focando-se na família, nas profissões, nos grupos onde se inseriam, na sociedade de pertença, nas relações que mantinham, entre outros, para, no fundo, criar linhas concretas dos seus percursos desde o nascimento até à idade atual.

Este processo foi facilitado pela disponibilidade e predisposição das três cuidadoras de idosos em colaborarem na pesquisa, e pela relação pré instituída entre investigador e atores sociais no âmbito dos contactos diários realizados num estágio curricular, o que permitiu criar alguma familiaridade, confiança e à vontade.

Enquanto cuidadoras formais de idosos, as três participantes permanecem há, pelo menos, dez anos na mesma instituição, o que leva a afirmar o interesse de cada uma no trabalho que exercem e, por sua vez, o interesse da instituição em mantê-las no ativo. Desenvolvem funções diferentes entre si, com horários distintos e em espaços diversos.

Todas as entrevistas, cujos nomes sofreram aqui alteração para garantir o seu anonimato, foram gravadas e, ulteriormente, transcritas fielmente, com o devido consentimento expresso, sendo, de seguida, analisadas e interpretadas a partir da categorização ou classificação das unidades em categorias, com o apoio das propostas enfatizadas por Roque Moraes (1999). Ademais, deu-se importância, ainda que não de forma exaustiva, à leitura intercultural (SCHÜTZE, in KÖTTIG \& VÖLTER, 2014), como forma de perceber se a religião ou a cultura exerciam influências nos seres profissionais que hoje são, já que as histórias de vida se inserem numa tradição que leva a que o investigador estude as influências socioculturais presentes no indivíduo (BRANDÃO, 2007) 


\section{O que nos contam estas histórias de vida?}

A partir da leitura dos dados recolhidos nas narrativas, como dissemos atrás, procedeuse à sua categorização e consequente subcategorização de elementos. Sublinhe-se que se prestou especial atenção àquilo que mais notoriedade se evidenciou nas narrativas de Ana, de Fernanda e de Edna, a fim de conhecermos em maior profundidade o processo (auto)formativo destas mulheres.

\section{A. Contexto Profissional}

\section{O contacto cuidadora e idosos}

No que concerne ao contacto, pretende-se enaltecer a empatia entre colaboradoras da instituição e utentes da instituição. A verdade é que exercer uma profissão de cuidado enfatiza o contacto direto e prolongado com os grupos com os quais se trabalha, podendo tal constituirse como uma vantagem ou uma desvantagem. Vejamos que, enquanto cuidadoras formais, as colaboradoras diariamente colmatam necessidades variadas de pessoas que têm níveis diferenciados de dependência. São, assim, presença indispensável e assídua nas vidas dos idosos que constantemente requerem cuidados e atenção.

Criam-se relações inter e intrapessoais que (também) quebram a fronteira profissional, de maneira a estabelecer-se um contacto mais aprimorado e baseado na confiança. Estamos a falar de um grupo alvo especial e, deveras, significativo.

$\mathrm{Na}$ verdade, quando questionadas sobre este aspeto, todas as narradoras enfatizaram a importância da relação estabelecida, quase como uma necessidade implícita que, aos poucos, vai quebrando os momentos de monotonia dos idosos, como nos diz Ana: "Eu estou sempre a brincar com eles.". O facto de todas as participantes afirmarem haver um contacto assíduo, demonstra a proximidade entre sujeitos.

\section{A profissão}

A profissão de cuidadora formal de idosos acarreta, inevitavelmente, importantes aspetos no que respeita ao foro emocional. Trabalhar diariamente com variadas necessidades pode, efetivamente, levar a desajustes emocionais. É uma profissão que, muito pelo contacto humano direto existente, obriga a uma regulação emocional maior, a fim de maximizar os limites da razão face às imposições da emoção, evitando-se descuidos sérios. As participantes sublinham o gosto pela profissão que mantêm há décadas. Face a escolhas que fizeram em 
algum momento das suas vidas, tomaram como opção trabalhar com pessoas da terceira idade, o que as desafia diariamente e as enriquece:

Ana: "Foi a minha escolha. Quando tirei o curso tinha 45 anos e fui fazer aquilo que mais queria”.

Fernanda: "Trabalhar com idosos, para mim ... para mim trabalhar com idosos, eu sei trabalhar com idosos. (...) Sabe o que é a gente ir de férias e ter uma pessoa que não fala, que não fala... Que é o caso da D. X. E a gente entrar na sala e ela dizer: "Olá! Onde esteve?” Ela sentiu a minha falta. Não é? (...) Por exemplo, aqui neste caso (apontando para o quarto de uma senhora que sofre de esquizofrenia) está sempre a perguntar quando é que vou de férias.".

Edna: "E o tratamento com os idosos... eles vão mudando, têm todos feitios diferentes, maneiras de ser diferentes, maneiras de pensar diferentes. (...) No entanto, nós temos de nos adaptar. Nem sempre eles têm razão, mas tem é de se saber dar a volta à situação conforme a conversa que estamos a ter e a situação que se está a propor e arranjar sempre da melhor maneira.".

\section{Andaimes formativos}

Os andaimes formativos são aprendizagens passadas que em algum momento e espaço da vida das colaboradoras as levaram a adquirir traquejo, autonomia, enriquecimento, aprendizagem pessoal e as ajudaram a adaptar-se a novas situações. Destacam-se outras atividades profissionais antecessoras das atuais, como forma de, voluntária ou involuntariamente, se retirar daí algum proveito.

Perante as respostas destas mulheres, a verdade é que nem sempre o fator ter experiência é eliminatório. Entre Ana, Fernanda e Edna, apenas a primeira se enquadra nesta situação, sublinhando que a vida no seu geral proporciona as maiores aprendizagens. Claro que quanto mais experiência e conhecimento daí provenientes o sujeito conseguir, melhor e mais apto está para exercer funções similares, porém, o trabalho diário é um extraordinário veículo de ensinamento e formação, por si só.

\section{B. Relações Interpessoais}

As relações interpessoais englobam aqui colegas e chefia no contexto de trabalho, principalmente, mas também as que se desenvolvem fora dos espaços profissionais. No que a estes grupos específicos diz respeito, as narradoras afirmaram que mantêm boas relações com as colegas de trabalho e com a chefia, sendo esta última baseada numa hierarquia imposta, mas, ao mesmo tempo, aceite. Boas relações nos locais de trabalho favorecem um clima de equipa 
estável, evitando-se conflitos internos. Muito através daquilo que é a estrutura relacional da pessoa, podem entender-se decisões, ações, formas de pensar; os sujeitos inseridos no seu próprio nicho social vão adquirindo muito daquilo que a sociedade lhes dá e, por inerência, aquilo que a sociedade lhes impõe.

\section{C. “Eu” Pessoal}

\section{As experiências de vida}

A categoria do "eu" pessoal integra o trajeto individual dos sujeitos em prol do trajeto profissional. As experiências de vida de cada participante foram narradas ao longo das entrevistas autobiográficas, constituindo-se como marcos importantes para cada uma. Cada estória liga-se a outra estória, perfazendo aquilo que é a história de vida do sujeito. O trabalho com idosos obriga a uma sensibilidade especial, porque este é um grupo que requer muitos cuidados de proximidade. Quando questionadas sobre a influência das experiências ao longo da vida nas profissões que hoje detêm, foi notória a rapidez de resposta. Claramente cada uma, com o seu estilo de vida, percurso, inserção na sociedade, têm nas suas respostas bases diferentes, motivos dissemelhantes que as levaram a afirmar que, realmente, as experiências no decurso dos seus trajetos as influenciam hoje enquanto seres profissionais. As histórias de vida são narradas consoante a memória do ator social e, por isso, a menção à infância, em momentos muito particulares como o recordar a forma como se foi educado, traz à conversa outros sujeitos que, de uma forma ou de outra, contribuíram para esse aspeto. Ainda que não diretamente mencionados, deduz-se que essa recordação implica outras pessoas e simboliza um espaço e momento formativo situado no passado e, agora, transposto para o presente. É importante que se sublinhe que o processo de análise de conteúdo permite a inferência através de uma intuição lógica sustentada pelo raciocínio, levando-nos a "reinterpretar as mensagens e a atingir uma compreensão dos seus significados" (MORAES, 1999, p. 2), no fundo, a ler nas entrelinhas:

Edna: “Sim, sim, muito, sempre. (...) A formação ... ou seja, a educação que nós levamos desde crianças influencia muito o nosso trabalho."

Ana: "Sim, muito. Foi tudo derivado da minha infância até agora."

\section{As marcas da vida}

As marcas da vida são cicatrizes deixadas pelos percursos individuais da vida de cada sujeito entrevistado. Por norma, cada estória é centrada num momento de dor, de alegria, de tristeza, de aprendizagem ou de outro qualquer sentimento que acaba por ditar grande parte da narrativa. É o chamado aspeto temático dominante (APPEL, 2005). Este núcleo central, 
emancipado pelo narrador e de onde surge a problemática fundamental, segue um fio condutor que permite entender as ligações do narrador às experiências sociais em que está inserido, permitindo que se entenda a ordem temporal do ator social no espaço social (APPEL, 2005). De forma mais ou menos clara, todas as participantes na pesquisa comunicaram aspetos que levaram à dedução dos seus núcleos principais.

Todos os marcos que foram ditando os percursos da Ana, da Fernanda e da Edna, são únicos e caracterizados, muitas vezes, pela dor e sofrimento. Ao mesmo tempo, há uma postura de superação em todas: o percurso de vida de Ana está marcado pela violência doméstica, desemprego, pelas doenças e perdas, não somente materiais, mas também humanas. Neste sentido, a importância da superação é, inequivocamente, o centro das atenções. O sujeito social que vive numa bola de negatividade durante anos e adota uma postura de combate que lhe permite vingar na vida, é um valente. Notou-se claramente a personalidade viva e brincalhona de Ana, no entanto, transmitia com seriedade o que realmente a marcou enquanto ser humano. Quanto à Fernanda, enaltece-se igualmente a postura de combate, quebrando com o tradicionalismo social mais ou menos imposto - foi aluna-adulta de um curso aos 43 anos, mostrando a capacidade de articular o tempo de estudo e o tempo de trabalho. Ganhou conhecimento, riqueza pessoal e experiência. Sublinha-se a determinação e motivação associadas a uma férrea vontade pessoal. Em Edna, é importantíssimo frisar a postura de combate, igualmente. Ficou órfã muito nova, tendo sido amparada por um colégio onde viveu como interna, e em que recebeu toda a sua educação e formação pessoal. Diz ter sido um período muito complicado, visto que a figura materna, como a conhecemos, não estava presente. Ainda assim, num dos momentos da entrevista há uma comparação entre o colégio interno e o local de trabalho, o que nos leva a afirmar que Edna tenha transmitido involuntariamente que, apesar das dificuldades que viveu e do longo período passado no colégio, este foi, realmente, indispensável e promotor da sua identidade pessoal.

\section{D. “Eu” Profissional}

\section{Desenvolvimento Profissional e Influência Formativa}

Quanto ao desenvolvimento profissional, os sujeitos entrevistados foram mencionando aspetos que enriqueceram o seu "eu" profissional ao longo da vida. Na verdade, o facto de Ana ter tido trabalhos com idosos no passado, ainda que pontuais, serviu de auxílio para ações similares nos dias de hoje, referindo assim uma transposição de conhecimento eficiente. É também relevante mencionar que há sempre aspetos importantes que, voluntaria ou involuntariamente, se retiram de contextos profissionais passados que pouco ou nada tenham a 
ver com os contextos atuais, como por exemplo, o contacto com pessoas, a gestão individual de tarefas ou a agilidade:

Fernanda: “(...) tenho uma boa bagagem de trabalho, mas todos os dias a gente aprende alguma coisa (...) com os idosos, todos os dias há uma novidade."

Edna: “(...) tendo uma boa formação num colégio, acho que me ajudou muito ao tratamento com os idosos. ".

No que diz respeito à influência formativa, esta manifesta-se como um importante veículo de valorização do capital humano, a fim de se investir nos recursos humanos a longo prazo. $\mathrm{O}$ facto de existirem formações específicas e variadas que propiciem um conhecimento prático e teórico sobre temáticas presentes nos contexto de trabalho é entendido como uma mais-valia. Formar-se é (trans)formar-se.

O trabalho com a terceira idade, tal como um vasto leque de profissões, disponibiliza o aperfeiçoamento do saber fazer por meio de práticas formativas que intervêm como forma de dinâmica profissional, consolidação de conhecimentos, construção de novos e atingimento de objetivos de carreira. Esta construção de novas aprendizagens exige, mormente, que se desconstruam outras 'aprendizagens', como forma de se livrarem de hábitos antigos e de dar atenção àquilo que hoje se faz e àquilo que é mais criativo (JOSSO, 2010). Esta é uma forma saudável dos sujeitos evitarem o conformismo e abrirem-se a novas ideologias de trabalho perante uma profissão onde existem algumas predisposições socioculturais, como é o caso das cuidadoras de idosos.

A par de qualquer outra profissão, a prática profissional e diária com idosos obriga a que se saiba o que fazer, como fazer e porque fazer. A formação presume trazer novidade e, como tal, "transformação, mudança" (JOSSO, 2010, p. 62) no sujeito que exerce a profissão.

Assim, particularmente no caso das profissões que se desenvolvem na interação entre pessoas, para lá das formações formais em cursos profissionais, a experiência desenvolvida por cada um no dia-a-dia, no contexto, na produção de conhecimento coletivo, são meios para alcançar conhecimento e enriquecimento pessoal, a fim de individualmente cada sujeito se tornar mais competente, mais proactivo na profissão e melhor consigo próprio.

De facto, as pessoas que se prontificaram a participar nesta investigação e a dar o seu testemunho autobiográfico, são pessoas adultas que nos permitiram, entre outros aspetos, a criação de uma reflexão biográfica, baseada nas suas experiências formadoras, nos seus processos de formação e de conhecimento, sendo, por isso, indivíduos que pertencem a uma 
categoria de sujeitos que dão reparo ao seu e nosso desenvolvimento pessoal e "às aprendizagens transformadoras de sua existência” (JOSSO, 2010, p. 62).

\section{E. Leitura Intercultural}

\section{A Cultura/Religião}

Perante os testemunhos individuais, deu-se conta da forte e sistemática menção de Ana a Deus. Como já foi mencionado, o percurso de vida de Ana foi marcado pelo sofrimento, sendo Deus a figura em que Ana encontra proteção e ajuda. Tudo em Ana revela uma postura de ensinamento e crença, transparecendo uma estabilidade emocional, pessoal e uma segurança em si. Apesar dos esforços e contratempos da sua vida, sublinha sempre que a mesma foi movida pelo destino e que para fazer aquilo que mais gosta profissionalmente foi necessário passar pelas arduidades que transcorreu. Esta ligação a Deus influencia, sem dúvida, a sua postura perante a vida e o reconhecimento da aprendizagem que dela retira:

Ana: "Eu aprendi muito. Aprendi a ser tolerante (...) a religião ajuda-nos muito (...) a ter fé (...) O conhecimento de Deus faz muita influência na nossa vida."

\section{As histórias de vida das narradoras nas marcas da sua ação profisssional - De tudo aquilo que as afasta enquanto seres humanos díspares, o que será que realmente as aproxima?}

Nesta fase, após análise cuidada das narrativas, estamos capazes de sublinhar aspetos inerentes a todas estas histórias de vida. No fundo são aspetos que decorrem da utilização desta metodologia investigativa. Digamos que podem ser considerados como características fundamentais que se desdobram em informações pertinentes e indispensáveis.

Realmente, não há dúvidas quanto ao uso fundamental, necessário e voluntário da memória, como forma de recordar momentos e episódios marcantes dos sujeitos. A memória é, talvez, o mais importante mecanismo aqui falado, permitindo o acesso, até então interdito, do investigador ao conhecimento.

Enquanto capital vital (SARMENTO, T. 2002), as histórias de vida permitiram um momento de testemunho pessoal onde o fator tempo (foi) é precioso. Na verdade, dar-se tempo ao narrador pode gerar detalhes que sugerem novos caminhos a explorar, distanciando-se a visão implícita do narrador enquanto mero objeto de estudo (TONON, 2006).

É importante sublinhar-se que o narrador não pode ser considerado como um comum objeto de estudo; não pode, portanto, ser materializado, mas, ao invés, tem que ser reconhecido como um ser humano produtor de conhecimento válido. 
Compreender o que provém das histórias de vida pode não ser um trabalho fácil, muito porque, como já se referiu, há um trabalho de inferência a realizar pelo investigador com base naquilo que foi narrado. Normalmente, as narrativas são geradas sem qualquer sequência temporal, até porque não há obrigatoriedade linear cronológica. Isso implica que esse trabalho seja realizado pelo investigador que analisa e interpreta as histórias de vida. No estudo que serve de alicerce a este artigo, a autora realizou tabelas ilustrativas dos percursos pessoais, profissionais e formativos, de modo a realizar a cronologia respeitante a cada trajeto e a facilitar a interação com o leitor. As participantes do estudo respeitaram, por isso, esta não linearidade implícita, o que leva a que se repare num fator importante: a abertura e flexibilidade da entrevista. Este é um aspeto normal, que enaltece a naturalidade da narrativa, sem grandes preparações nem textos decorados. Essa naturalidade aliada a cada entrevista narrada, conferelhe singularidade; as histórias são, por isso, "casos particulares" (PRADO \& SOLIGO, 2005). $\mathrm{Na}$ voz das três cuidadoras encontra-se, portanto, a concretização de um momento surpreendente e vanguardista, definido exatamente por essa singularidade (PRADO \& SOLIGO, 2005).

A necessidade de se expor existe, ainda que não seja facilmente visível. Se se reparar nesta ligação de estórias contadas pelas participantes, motivadas pelas questões que foram sendo colocadas, nota-se a vontade em mostrar o seu verdadeiro Eu, até porque a oportunidade de se narrarem não acontece diariamente e a vontade de se presenciarem naquele momento e testemunharem face aos seus percursos cria reflexões riquíssimas, promovendo uma liberdade que se vê de dentro para fora, sentindo-se respeitadas e valorizadas.

Quando se questiona se, efetivamente há conhecimento proveniente das histórias de vida para a prática profissional ou pessoal de um determinado sujeito, parece claro afirmar que sim. Os espaços onde a investigação se desenrolou permitiram reconhecer aspetos preciosos da vida profissional das participantes, bem como identificar possíveis necessidades, observar a interação, capacidade de gerir emoções, trabalho em equipa, capacidade de resposta. As narrativas individuais vieram unir a observação do presente (objetividade), pela investigadora, à subjetividade do passado, pelo narrador.

Estas conversas, mormente os relatos (auto)biográficos aqui registados, são testemunhos verdadeiramente ricos, capazes de criar auto reflexão e, acima de tudo, auto consciencialização no sujeito. Por meio dos encontros, formais e informais, tidos com as participantes, essa consciência dos factos vividos ia sendo realçada, por vezes, com um simples "já não me recordava disto" ou "já não falava disto há tanto tempo". Esta oportunidade de testemunhar e vontade de o fazer trazem um melhoramento pessoal a vários níveis, elevando o 
sujeito a uma entidade (trans)formadora de si mesma. O reviver momentos do passado, arduidades, trajetos, sentimentos e pessoas que já partiram, contribuíram para a compreensão da realidade social de cada entrevistada no momento em que contavam as suas histórias face ao momento em que elas realmente aconteceram, para a compreensão da relação do indivíduo com a estrutura social que o alberga, para a compreensão das ações executadas pelos indivíduos dentro dos seus sistemas e, acima de tudo, para a compreensão de si mesmos enquanto seres humanos.

É através do próprio depoimento que o sujeito toma consciência do que experienciou e se auto forma, permitindo que o investigador também o faça. Afinal, cada narrativa é única e tende a ensinar de forma diferente. $\mathrm{Na}$ verdade, de tudo aquilo que as afasta enquanto seres humanos díspares, há muito que realmente as aproxima enquanto profissionais do mesmo ofício. Para além das características presentes em todas as narrativas e que as aproxima enquanto seres autobiográficos e emancipadores de si, há aspetos que temos de salientar: o espaço e o público de trabalho, o género e a sua preferência para atividades de cuidado, a capacidade de superação, a postura de combate, as perdas, a arte de cuidar, o interesse pelo Outro, a subjetividade, o testemunho, a capacidade de auto consciência ou a disponibilidade para a auto aprendizagem; todos estes aspetos que promovem um mesmo traçado notório em todas as cuidadoras, um caminho propício à evolução do sujeito e formador em potencial.

Podemos concluir que as histórias de vida devem ser entendidas como um meio extremamente único para atingir um conhecimento científico alargado de percursos identitários, onde se criam perfis distintos, ricos, singulares e onde o testemunho de superação e reconhecimento de si existe em prol da autoformação.

Do passado, retiram-se as aprendizagens necessárias à sobrevivência no presente e, continuamente, enriquece-se a bagagem das experiências de vida, criando-se novas bases para o futuro. O passado cruza-se com o presente em prol do futuro, numa tentativa de não se quebrar o ciclo.

As histórias de vida manifestam-se como um desenho das experiências de cada sujeito que cruzam com a formação para que esta possa dar cor e sentido ao que é feito e ao que é visto pelo sujeito, desenvolvendo-se um trabalho impactante em detrimento da sua transformação.

Ao terminar este artigo, prestamos homenagem a todas as Anas, Fernandas e Ednas, cuidadoras de idosos, que pelo mundo fora, nesta terrível fase da pandemia do covid-19, são um grande sustentáculo para o seu bem-estar, os quais, como afirma António Guterres, secretário-geral das Nações Unidas, "têm o mesmo direito à vida e à saúde que as outras pessoas. Ninguém, jovem ou velho, é prescindível". Numa profissão do humano, as cuidadoras 
de idosos, com o seu saber, o seu fazer e o seu Ser, manifestam estar presentes nesta luta, manifestando acreditar que "Para ultrapassarmos juntos esta pandemia, precisamos de aumentar a solidariedade global e nacional e os contributos de todos os membros da sociedade, incluindo os idosos" (GUTERRES, maio 2020).

\section{REFERÊNCIAS}

ANSART, Pierre. Percursos de memórias em terras de história: problemáticas atuais. In: BRESCIANI, Stella \& NAXARA, Márcia (orgs.). Memória e (res)sentimento: Indagações sobre uma questão sensível. Campinas, SP: Editora da Unicamp, 2001. p.15-36.

APPEL, Michael. La entrevista (auto)biográfica narrativa: Fundamentos teóricos y la praxis del análisis mostrada a partir del estudio de caso sobre el cambio cultural de los Otomíes en México. Forum: Qualitative Social Research, vol. 6, n. 2, artigo 16. 2005. 35p. ISSN 14385627. PDF.

ARAÚJO, Mónica. Os Contributos das Histórias de Vida de Colaboradoras na Prática Profissional com Idosos. 187f. Dissertação (Mestrado em Educação - Formação, Trabalho e Recursos Humanos). Universidade do Minho, Gualtar, Braga, 2019.

BRANDÃO, Ana Maria. Entre a vida vivida e a vida contada: A história de vida como material primário de investigação sociológica. Universidade do Minho, Braga, 2007.

DELORY-MOMBERGER, Christine. Formação e socialização: os ateliês biográficos de projeto. Educação e Pesquisa, n.3. São Paulo, 2006. 12p. ISSN 1517-9702.

FREIRE, Paulo. Pedagogia do Oprimido. Rio de Janeiro: Paz e Terra, 1970. 107p.

GUTERRES, António. Relatório com análises e recomendações para enfrentar desafios. ONU. https://news.un.org/pt/story/2020/05/1712232. Acessado em 30 de setembro de 2020.

JOSSO, Marie-Christine. Experiências de Vida e Formação. 2. ed. São Paulo: Editora da UFRN, 2010.

LECHNER, Elsa (org). Histórias de vida: olhares interdisciplinares. Porto: Edições Afrontamento, 2009.

MORAES, Roque. Análise de conteúdo. Revista Educação, n.37. Porto Alegre, 1999. 35p. PDF.

PINEAU, Gaston. As Histórias de Vida em Formação: Génese de uma corrente de pesquisa-ação-formação existencial. Vol. 32, n.2. São Paulo, 2006. 14p

POLLACK, Michael. Memória e identidade social. Estudos Históricos. Vol. 5, n. 10. Rio de Janeiro, 1992. 12p.

PRADO, Guilherme do Val Toledo \& SOLIGO, Rosaura. (org.). Memorial de Formação quando as memórias narram a história da formação. In: PRADO, G. \& SOLIGO, R. 
(Org.). Porque escrever é fazer história: revelações, subversões, superações. Campinas: Alínea, 2005. p. 42-60.

RIBEIRO, Maria \& Santos Rosângela (2000). O método "história de vida" e seu uso em pesquisa de enfermagem com gestante HIV positivo. Escola Anna Nery Revista de Enfermagem $n^{\circ}$ 1. Págs. 46-54.

RICOEUR, Paul. A Metáfora Viva. Porto: Rés-Editora, 1983

SARMENTO, Teresa. Histórias de vida de educadoras de infância. Lisboa: Instituto de Inovação Educacional, 2002.

SEIXAS, Jacy Alves de. Percursos de memórias em terras de história: problemáticas atuais. In: BRESCIANI, Stella \& NAXARA, Márcia (orgs.). Memória e (res)sentimento:

Indagações sobre uma questão sensível. Campinas, SP, Editora da Unicamp: 2001. p. 37-58

TONON, Luciane. Narrativas biográficas: da busca à construção de um método. In: RUBIO, Katia (org.), A narrativa como linguagem na construção da memória. São Paulo, Képos: 2006. P. 121-135

KÖTTIG, Michaela \& Völter, Bettin. "Isso, sim, é ser sociólogo!” - Uma entrevista narrativa com Fritz Schütze sobre a história de sua obra na sociologia. Civitas - Revista de Ciências Sociais, $\mathrm{n}^{\circ} 2$. Porto Alegre, 2014. 22p. ISSN 1984-7289. PDF.

\section{Agradecimento}

Este trabalho foi financiado por Fundos Nacionais através da FCT - Fundação para a Ciência e a Tecnologia no âmbito do projeto do CIEC (Centro de Investigação em Estudos da Criança da Universidade do Minho) com a referência UIDB/00317/2020.

\section{SOBRE AS AUTORAS:}

\section{Mónica Pires Araújo}

Mestre em Educação, na vertente de Formação, Trabalho e Recursos Humanos; Universidade do Minho (UM). E-mail: monica_piresaraujo@ hotmail.com

(iD https://orcid.org/0000-0001-0738-295X

\section{Teresa Sarmento}

Doutora em Estudos Socio Educativos, pela Universidade do Minho, Braga, Portugal. Professora Auxiliar do Departamento de Ciências da Educação, Investigadora do Centro de Investigação em Estudos da Criança, Instituto de Educação, Universiade do Minho. E-mail: tsarmento@ie.uminho.pt

(iD https://orcid.org/0000-0002-2371-399X 